\title{
Immunology and Genetics of Type 1 Diabetes
}

\author{
Michael P. Morran, ${ }^{1}$ Gilbert S. Omenn ${ }^{2}$ and Massimo Pietropaolo ${ }^{1}$ \\ ${ }^{1}$ Laboratory of Immunogenetics, Brehm Center for Type 1 Diabetes Research and Analysis, Division of \\ Metabolism, Endocrinology, and Diabetes, Department of Internal Medicine, University of Michigan Medical \\ School, Ann Arbor, MI \\ ${ }^{2}$ Center for Computational Medicine and Biology, Departments of Internal Medicine and Human Genetics, \\ University of Michigan, Ann Arbor, MI
}

\begin{abstract}
Type 1 diabetes is one of the most well-characterized autoimmune diseases. Type 1 diabetes compromises an individual's insulin production through the autoimmune destruction of pancreatic $\beta$-cells. Although much is understood about the mechanisms of this disease, multiple potential contributing factors are thought to play distinct parts in triggering type 1 diabetes. The immunological diagnosis of type 1 diabetes relies primarily on the detection of autoantibodies against islet antigens in the serum of type 1 diabetes mellitus patients. Genetic analyses of type 1 diabetes have linked human leukocyte antigen, specifically class II alleles, to susceptibility to disease onset. Environmental catalysts include various possible factors, such as viral infections, although the evidence linking infections with type 1 diabetes remains inconclusive. Imbalances within the immune system's system of checks and balances may promote immune activation, while undermining immune regulation. A lack of proper regulation and overactive pathogenic responses provide a framework for the development of autoimmune abnormalities. Type 1 diabetes is a predictable and potentially treatable disease that still requires much research to fully understand and pinpoint the exact triggering events leading to autoimmune activation. In silico research can aid the comprehension of the etiology of complex disease pathways, including Type I diabetes, in order to and help predict the outcome
\end{abstract}

\section{Address Correspondence to: \\ Massimo Pietropaolo \\ Laboratory of Immunogenetics \\ Brehm Center for Type 1 \\ Diabetes Research and Analysis \\ Ann Arbor, MI \\ Email: maxtp@umich.edu}

of therapeutic strategies aimed at preserving $\beta$-cell function. Mt SinaiJ Med 75:314-327, 2008. () 2008 Mount Sinai School of Medicine

Key Words: adaptive immunity, autoimmunity, genetics in type 1 diabetes, innate immunity, type 1 diabetes.

\section{IMMUNE SYSTEM REVIEW}

The immune system is the body's natural defense system against invading pathogens. It protects the body from infection and works to communicate an individual's well-being through a complex network of interconnected cells and cytokines. This system has the power to initiate a wide gamut of cellular responses with the ability to directly attack an invading organism or signal cells to begin the healing process. Although this system is an associated host defense, an uncontrolled immune system has the potential to trigger negative complications in the host. Therefore, well-controlled regulation of the immune system is necessary in order to prevent autoimmune responses from occurring.

In order to protect the body against foreign pathogens, the immune system has developed throughout evolution to recognize the difference between the self and nonself. The ability to become self-tolerant toward the body's own proteins and antigens is critical to maintaining a properly functioning immune system. An immune system that loses tolerance to the self loses the ability to differentiate between friend and foe in immunological battles. Loss of tolerance leads the immune system toward autoimmune responses, in which the body attacks itself, causing substantial damage to the self, even inflicting irreversible damage.

The immune system is composed of 2 unique branches, each with its own responsibilities. The 
T1D Development

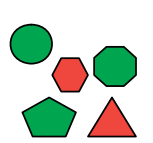

Contributing Factors

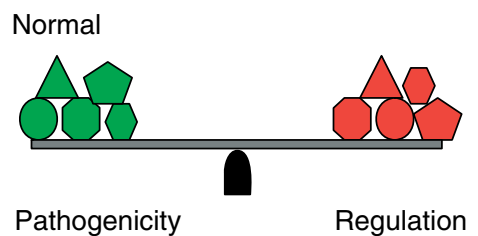

T1D Protected

T1D Prone

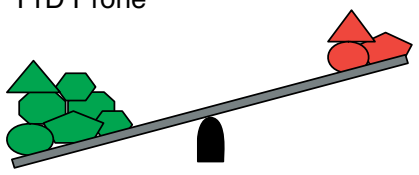

Pathogenicity

Regulation

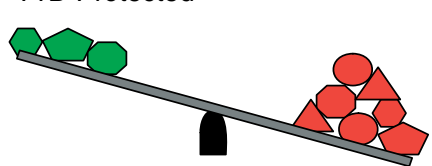

Pathogenicity
Regulation

Fig 1. T1D development. A discrete balancing act is performed by the immune system in order to attack foreign pathogens while protecting against the promotion of autoimmunity. Multiple contributing factors influence the development of T1D, including genetics, the environment, and cellular signals. In a normal individual the immune system is balanced, possessing the ability to both promote and suppress cellular responses to pathogens. When an immune system is unbalanced and favors inflammation or excessive cellular responses, the system is unbalanced and favors excesive regulation of cellular responses, the system is protected against the development of T1D and autoimmunity. Abbreviations: T1D, type 1 diabetes. Adapted from Annual Review of Immunology. ${ }^{102}$ [Color figure can be viewed in the online issue, which is available at www.interscience.wiley.com.].

innate immune system is the body's first line of defense against invading pathogens. This system recognizes common structural components of pathogens and elicits immune responses to signal the presence of pathogens and infection. ${ }^{1}$ The adaptive immune system is the body's secondary line of defense and specifically targets identified pathogens. This system is antigen-specific and generates immunological memory within the host, which allows for more efficient pathogen clearance upon repeat exposure to the same pathogen. ${ }^{1}$ Although these 2 systems are termed different branches of the immune system, they must work together as one unified system to protect the body. The 2 branches of the immune system rely on each other to help properly perform their jobs. If either branch fails to perform its job, the other branch suffers. Regulatory malfunctions in either system can ultimately lead to the generation of unwarranted or unregulated autoimmune responses. Underlying an immune response lies a delicate network of cell types and cytokines that communicate to begin, generate, and end an immune response. If an immune system becomes unbalanced, this delicate network, responsible for preventing autoimmunity, promotes it (Figure 1).

The immune system protects the host, but it also possesses the power to harm the host as well. Numerous autoimmune diseases have been characterized over time. This article provides an overview of how alterations in the immune system, due to genetics, cellular malfunctions, or cell signaling issues, lead to the development and pathogenesis of autoimmune diseases, specifically type 1 diabetes (T1D). Understanding mechanistically how T1D and autoimmune responses are triggered is essential in order to develop strategies to combat these diseases.

\section{TYPE 1 DIABETES OVERVIEW}

Diabetes mellitus is a group of diseases characterized by the body's inability to accurately maintain normal blood glucose levels, leading to multiple detrimental effects. Insulin is an important hormone in glucose metabolism. When released, it signals cells to take up glucose. If the body is unable to produce insulin, blood glucose levels remain elevated, and this is termed hyperglycemia. T1D is an autoimmune disease in which the immune system targets and destroys the insulin-producing $\beta$-cells found in the islets of Langerhans in the pancreas. Without insulin, individuals develop the clinical syndrome of T1D.

T1D is characterized by autoantibody production and progressive infiltration of immune cells into 
the islets of the pancreas, followed by the destruction of the islet cells. ${ }^{2}$ During the onset of T1D, cells from both the innate and adaptive immune systems infiltrate islet lesions to produce insulitis. Studies using human and murine models of diabetes have demonstrated that the autoimmune destructive process in T1D occurs in a cell-mediated organ-specific manner and requires both $\mathrm{CD}+4$ and $\mathrm{CD}+8 \mathrm{~T}$ cells as well as macrophages. ${ }^{3-13}$ These cells accumulate in an islet lesion but are nondestructive. ${ }^{14-16}$ An unknown triggering event occurs, which promotes the autoimmune destruction of the $\beta$-cells. ${ }^{14-16}$ Clinical manifestations of diabetes occur after $90 \%$ of an individual's $\beta$-cell mass is destroyed. ${ }^{14}$

The exact trigger for the onset of T1D is still unknown, as discussed later, although the mechanism by which the insulin-producing $\beta$-cells are destroyed is well understood. The destructive process is $\mathrm{T}$ cell-mediated. Once the islets have become infiltrated and highly populated with $\mathrm{T}$ cells and macrophages, a subsequent triggering event occurs to activate these cells. ${ }^{14-16} \mathrm{~T}$ cells, B cells, and macrophages communicate via antigen presentation and can, in turn, activate each other via cytokines and direct cell communication through surface receptors. ${ }^{1}$ With such a high population of immune cells centered in one distinct area, activation signals can travel fast, initiating a destructive cascade easily.

In general, macrophages play the role of antigenpresenting cells (APCs), and so they can directly pick up and present $\beta$-cell antigens. This leads to the activation of $\beta$-cell-cytotoxic $\mathrm{CD}+8 \mathrm{~T}$ cells and the generation of autoreactive $\mathrm{CD}+4$ effector T cells. ${ }^{15}$ Cytotoxic $\mathrm{T}$ cells can directly kill $\beta$-cells, whereas effector $\mathrm{T}$ cells can initiate the activation of $\mathrm{B}$ cells, thus prompting autoantibody production. ${ }^{15}$ Once the immune system is triggered or activated, it begins to process and present self antigens to $\mathrm{T}$ cells, generating the autoimmune process that leads progressively to the clinical manifestations of T1D.

T cells possess the ability to directly destroy $\beta$ cells in a cytotoxic manner but also hold the power to directly influence the induction of $\beta$-cell destruction through the release of cytotoxic molecules, including cytokines, granzyme B, and perforin. ${ }^{16,17}$ T cells can also signal $\beta$-cell death through the Fas pathway. ${ }^{16,17}$ $\beta$-Cell apoptosis is promoted by activation of the caspase pathway through multiple mechanistic pathways, including Fas and Fas ligand interactions, nitric oxide and oxygen-derived free radicals, and membrane disruption due to perforin or granzyme B. ${ }^{18}$ Cytokine production by activated $\mathrm{T}$ cells may be a key factor in $\beta$-cell death, influential cytokines released by $\mathrm{T}$ cells include: interleukin 1 (IL-1), interferon $\gamma$ (IFN $\gamma)$, and tumor necrosis factor $\alpha(\operatorname{TNF} \alpha)$, all of which up-regulate Fas and the production of Fas ligand, nitric oxide, and freeradicals. ${ }^{18,19}$ Other notable cytokines are IL-2, IL-12, IL-17, and IL-18, all of which seem to promote an inflammatory state biased to $\mathrm{T}$ helper 1 type responses. ${ }^{18,19}$

\section{AUTOANTIGENS IN TYPE 1 DIABETES}

During the progression of T1D, multiple autoimmune processes occur. Human and murine studies of T1D have illustrated that, as the severity of disease increases, so does the number of autoantigens and autoantibodies. ${ }^{20}$ Over the course of development, $\beta$-cells go through multiple divisions and changes in cell volume and increase in cell mass. ${ }^{21}$ During this time, $\beta$-cells grow, develop, and eventually die; these dead cells may be engulfed and processed by APCs. In an insulitis lesion, these APCs presenting processed $\beta$-cell components have the potential to trigger the generation of $\beta$-cell autoreactive $\mathrm{T}$ cells. ${ }^{14-16,21}$

Most well-known autoantigens are associated with $\beta$-cell components, including insulin, glutamic acid decarboxylase (GAD), and islet-cell antigen-2 (IA-2) ${ }^{20}$ Insulin is the first antigenic target detectable during the early progression of diabetes, ${ }^{22}$ although most autoantibodies are targeted against the $\beta$ cells themselves and other $\beta$-cell-secreted proteins. ${ }^{20}$ Recently, ZnT-8, a pancreatic $\beta$-cell-specific zinc transporter, has been identified as a candidate autoantigen. ${ }^{23}$ Although research is limited on this molecule, strong evidence already supports the association of ZnT-8 autoantibodies with T1D. ${ }^{23}$ During the progression of $\mathrm{T} 1 \mathrm{D}$, a process of autoantigen epitope spreading occurs. ${ }^{24}$ Epitope spreading provides an explanation of how the immune system is capable of recognizing increasing numbers of autoantigens in correlation with increased T1D disease severity. ${ }^{24}$ Epitope spreading begins with the immune system recognizing and mounting an immune response against a single antigen, which is recognized via a single epitope. Over time, new antigens can be recognized, and previously recognized antigens can be differentially processed by APCs to generate multiple epitopes for a single antigen.

One can think of this process as similar to a tree growing toward autoimmunity. In Figure 2, the tree stem symbolizes an immune system at birth that lacks autoimmunity. As this tree grows 
Auto-Antigen Epitope Spreading in T1D

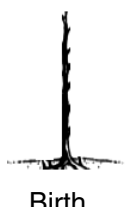

Birth

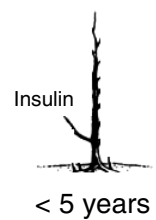

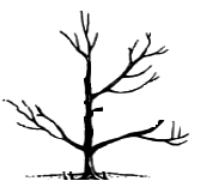

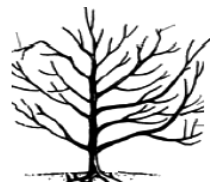

Autoimmune Disease Progression

Fig 2. Autoantigen epitope spreading in T1D. As the severity of symptoms associated with T1D increases over time, so does the number of autoantigens recognized by the immune system. Epitope spreading begins once the immune system is triggered within the pancreas, leading to the processing and presentation of self antigens. As $\beta$-cell destruction takes place, multiple self antigens become targets of the immune system. During this process, insulin is the first antigenic target, ${ }^{22}$ and it is followed by other $\beta$-cell-associated components, such as GAD65 and IA-2. ${ }^{20}$ Over time, autoantigens are processed differently, creating various recognition epitopes for a given antigen. In Figure 1, the tree symbolizes an immune system at birth that lacks autoimmunity. As the tree grows toward autoimmune T1D, its limbs represent targeted self antigens that develop. As T1D progresses, multiple limbs grow off the tree, each from a different antigen. These growing limbs next branch off, representing the unique epitopes recognized from differential processing of similar self peptides. As T1D develops, the tree grows toward autoimmunity by increasing both the number of limbs and the number of branches on a given limb, representing the process of epitope spreading observed in T1D disease development. Abbreviations: GAD65, glutamic acid decarboxylase 65; IA-2, islet-cell antigen-2; T1D, type 1 diabetes.

toward autoimmune T1D, its limbs represent developing targeted self antigens. Next, multiple limbs grow from the stem, each targeting different antigens. These growing limbs branch off, representing the unique epitopes recognized from differential processing of similar peptides. It has been shown that autoantibody production has been detected up to 5 years prior to the development of hyperglycemic events, and this indicates that autoantibody production precedes the clinical manifestation of T1D. ${ }^{24}$ As T1D develops, the tree grows toward autoimmunity by increasing both the number of limbs (targeted antigens) and the number of branches on a given limb (recognized epitopes for a particular antigen). Although the progression and mechanisms behind the development of T1D are understood in general terms, many questions remain to be answered concerning how the autoimmune disease state becomes triggered toward autoreactivity.

We have provided evidence suggesting that a subset of cytoplasmic islet-cell antibodies (ICAs) is related to a more rapid progression to insulinrequiring diabetes in glutamic acid decarboxylase 65 (GAD65) and IA-2 antibody-positive relatives of proband patients versus relatives with GAD65 and IA-2 antibodies without ICAs (Figure 3). ${ }^{25}$ The precise nature of the antigen(s) detected by the indirect immunofluorescence ICA assay remains enigmatic, but its utility to predict future development of diabetes mellitus in individuals with other circulating ICAs has recently been confirmed.

\section{WHAT ARE THE GENES ASSOCIATED WITH TYPE 1 DIABETES?}

Although it has been suggested that multiple genes play a role in disease susceptibility, there is strong evidence for only 2 chromosomal regions that are associated with T1D: the human leukocyte antigen (HLA) region on chromosome 6p21 [insulindependent diabetes mellitus 1 (IDDM1)] and the insulin gene region on chromosome $11 \mathrm{p} 15$ [insulindependent diabetes mellitus 2 (IDDM2)]. The contributions of these 2 loci to familial inheritance are approximately $42 \%$ for $I D D M 1$ and $10 \%$ for $I D D M 2$. As a result of genome-wide searches, many other putative loci have been proposed to be related to T1D. These loci along with some potential candidate genes are listed in Tables 1 and 2. The fact that in humans the highest risk-conferring locus linked to the disease is the HLA cluster and, in particular, HLA genes encoding specific class II alleles strongly indicates an important role of the immune cells in both the development and activation of the autoimmune response leading to disease onset. ${ }^{26}$ 
(A)

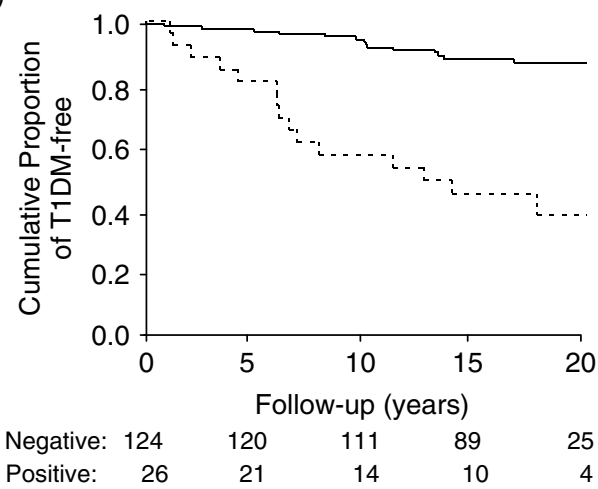

(C)

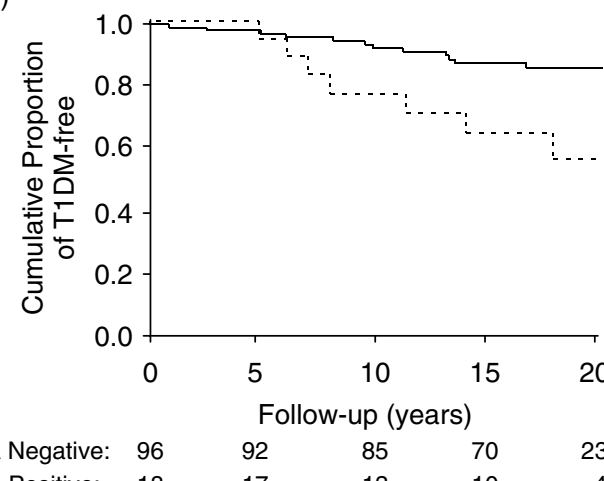

(B)

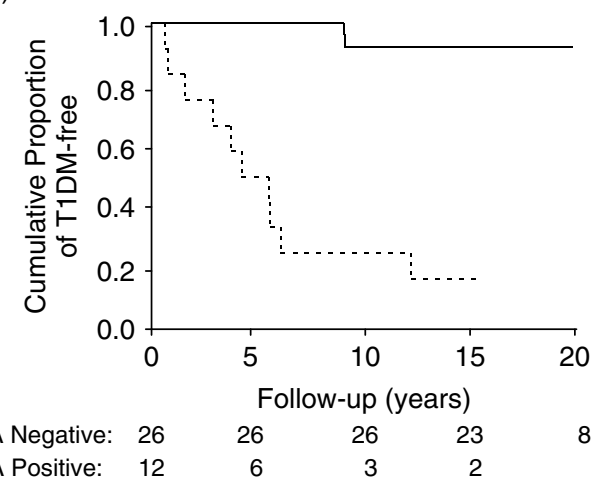

(D)

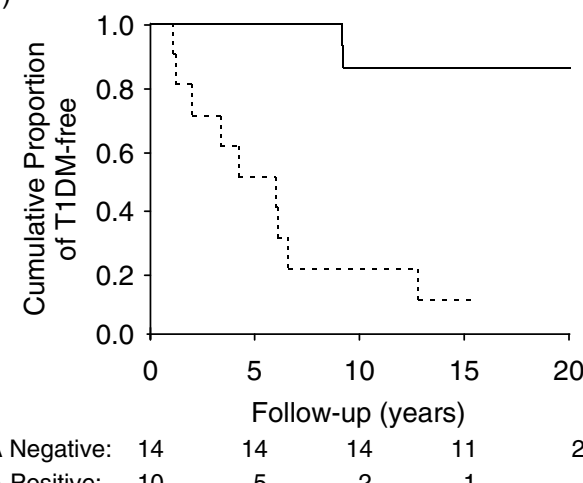

Fig 3. The rate of progression to T1DM development in relatives carrying GAD65 AA, IA-2 AA, or a combination of both AA in the (-) absence or (- - ) presence of ICA. (A) Progression to insulinrequiring diabetes for relatives with GAD65 AA with respect to ICA positivity. (B) Progression to insulin-requiring diabetes for relatives with IA-2 AA with respect to ICA positivity. (C) Progression to insulin-requiring diabetes for relatives with either GAD65 or IA-2 AA with respect to ICA positivity ( $\log$ rank: $P=0.01$ ). (D) Remarkably, the cumulative risk of developing an insulin requirement was $80 \%$ at 6.7 years and $90 \%$ at 12.9 years of follow-up in ICA-positive relatives; this is significantly higher than the cumulative risk of diabetes development in relatives who were positive for GAD65 and IA-2 AA without ICA (log rank: $P<0.00001$ ). Abbreviations: AA, auto-antibodies GAD65, glutamic acid decarboxylase 65; IA-2, islet-cell antigen-2; ICA, islet-cell antibody; T1DM, type 1 diabetes mellitus. Reprinted with permission from Pediatric Diabetes. ${ }^{25}$ Copyright 2005, International Society for Pediatric and Adolescent Diabetes.

Interestingly, the same HLA locus seems to have the corresponding susceptibility influence in the primary mouse model of T1D, the nonobese diabetic (NOD) mouse (Table 3). ${ }^{27}$ The immune-mediated processes of $\beta$-cell destruction are mainly $\mathrm{T}$ cell-dependent and chronic in both mouse and rat models of T1D, and this makes it more likely to be the same in humans. ${ }^{27}$ Comparative mapping of human (IDDM) and NOD mouse insulin-dependent diabetes (Idd) genes are shown in Table 3.

Genetic factors have long been thought to be linked to the development of T1D. Although it has been hypothesized that in monozygotic twins a discordance rate greater than $50 \%$ could be explained by environmental factors of disease development, studies using both monozygotic and dizygotic twins have suggested that environmental factors have few causative roles in the development of islet autoimmunity, whereas genetic similarities in dizygotic twins seem more important in determining susceptibility to diabetes. ${ }^{28}$ T1D is a polygenic disease $^{29}$ in which there presumably exist a small number of genes with large effects, HLA being the main example, and a large number of genes with small effects overall. ${ }^{30}$

\section{THE HUMAN LEUKOCYTE ANTIGEN COMPLEX}

The short arm of human chromosome 6 (6p21) accommodates $\mathrm{a} \sim 3.5$-megabase genetic segment containing a group of immune response genes 
Table 1. Effect of Human Leukocyte Antigen Alleles on Type 1 Diabetes Susceptibility.

\begin{tabular}{|c|c|c|}
\hline DQ Alleles & Effect & Associated DR \\
\hline $\mathrm{B} 1^{*}$ 0302, A1* 0301 & Susceptible & DR4 \\
\hline $\mathrm{B} 1 *$ 0201, A1* 0501 & Susceptible & DR3 \\
\hline $\mathrm{B} 1 * 0501, \mathrm{~A} 1 * 0101$ & Susceptible & DR1 \\
\hline B1* 0201, A1* 0301 & Susceptible (African Americans) & DR7 \\
\hline $\mathrm{B} 1 * 0502, \mathrm{~A} 1 * 0102$ & Susceptible (Sardinia) & DR2 (DR16) \\
\hline $\mathrm{B} 1 * 0303, \mathrm{~A} 1 * 0301$ & Susceptible (Japanese) & DR4 \\
\hline $\mathrm{B} 1 * 0303, \mathrm{~A} 1 * 0301$ & Susceptible (Japanese) & DR9 \\
\hline $\mathrm{B} 1 * 0602, \mathrm{~A} 1 * 0102$ & Protective & DR2 (DR15) \\
\hline $\mathrm{B} 1 * 0301, \mathrm{~A} 1 * 0501$ & Protective & DR5 \\
\hline B1* 0201, A1* 0201 & Neutral & DR7 \\
\hline $\mathrm{B} 1 * 0303, \mathrm{~A} 1 * 0301$ & Neutral & DR4 \\
\hline $\mathrm{B} 1 * 0301, \mathrm{~A} 1 * 0301$ & Neutral & DR4 \\
\hline
\end{tabular}

Table 2. Genetic Risk Estimates for Human Leukocyte Antigen Class II in T1D.

\begin{tabular}{ll}
\hline High-Risk Genotype & $\begin{array}{c}\text { Risk in an } \\
\text { Individual } \\
\text { with This } \\
\text { Genotype }\end{array}$ \\
\hline DQB1* 0302 (DQ3.2) & 1 in 60 \\
DQ3.2/DQ2 (DR3) & 1 in 25 \\
DQB1* 0302 and a family history of IDDM & 1 in 10 \\
DQ3.2/DQ2 (DR3) and a family history of T1D & 1 in 4 \\
\hline NOTE: This table was adapted from Annual Review of \\
Medicine.
\end{tabular}

Abbreviations: IDDM, insulin-dependent diabetes mellitus; T1D, type 1 diabetes.

termed the major histocompatibility complex (MHC). The principal genes located within the MHC code for HLAs, 2 molecular classes of cell surface glycoproteins differing in structure, function, and tissue distribution.

The class I HLA molecule exists as a heterodimer, consisting of a polymorphic 44-kDa MHC-encoded $\alpha$ or heavy chain in noncovalent association with $\beta_{2}$-microglobulin, a $12-\mathrm{kDa}$ protein encoded by a nonpolymorphic gene on chromosome 15 . The class I molecule is anchored in the cell membrane only by the heavy chain. This chain contains 338 amino acids and, beginning from the amino terminus, is functionally divided into 3 regions: an extracellular hydrophilic region, a transmembrane hydrophobic region, and an intracytoplasmic hydrophilic region. The extracellular region is further subdivided into 3 domains, designated $\alpha_{1}, \alpha_{2}$, and $\alpha_{3}$, each of which has approximately 90 amino acid residues. The $\alpha_{1}$ and $\alpha_{2}$ domains compose the peptide- or antigenbinding region of the molecule.

Class II HLA molecules consist of 2 glycoprotein chains, an $\alpha$ chain of approximately $34 \mathrm{kDa}$ and a $\beta$ chain of approximately $29 \mathrm{kDa}$, both encoded within the MHC. As with the class I heavy chain, each class II chain can be divided into 3 regions (extracellular, transmembrane, and intracytoplasmic), but in contrast, both class II chains span the cell membrane. Each extracellular region of the class II $\alpha$ and $\beta$ chains has been further divided into 2 domains of approximately 90 amino acid residues each, termed $\alpha_{1}$ and $\alpha_{2}$ and $\beta_{1}$ and $\beta_{2}$, respectively. The $\alpha_{1}$ and $\beta_{1}$ domains form the peptide-binding region of class II HLA molecules. Also of note, the class II $\alpha_{2}$ and $\beta_{2}$ domains, class I $\alpha_{3}$ domain, and $\beta_{2}$-microglobulin all show homology to the constant region of immunoglobulins and are therefore classified as members of the immunoglobulin superfamily.

The genes that encode class I MHC are located at the HLA-A, HLA-B, and HLA-C loci, whereas class II molecules are encoded by the DR, DQ, and DP genes. Other genes in this cluster include transporters associated with antigen processing ${ }^{31,32}$ and low-molecular-weight proteins, both of which are involved in antigen processing. ${ }^{33} \mathrm{~A}$ third region of the MHC, termed class III, encodes several molecules having a variety of functions, such as complement 
Table 3. Comparative Mapping of Human (IDDM)and Murine (Idd) Genes.

\begin{tabular}{|c|c|c|c|}
\hline Human Locus (Chromosome) & $\begin{array}{c}\text { Marker/ } \\
\text { Candidate }\end{array}$ & Potential NOD “Idd” Homolog (Chromosome) & Marker \\
\hline IDDM1 (6p21) & HLA & "Idd1" (17) = n & $\mathrm{H} 2 \mathrm{~g} 7$ \\
\hline IDDM2 (11p15.5) & INS/VNTR & ? NOD.DR-2 (chromosome 7 region from C57L) & ? Ins2 \\
\hline$I D D M 3(15 \mathrm{q} 26)$ & D15S107 & 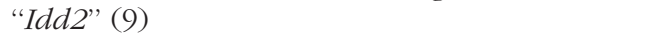 & Cyp19 \\
\hline IDDM4 (11q13) & FGF3 & None yet identified (distal 7) & \\
\hline IDDM5 (6q25) & ESR & None yet identified (proximal 10) & \\
\hline $\operatorname{IDDMG}(18 \mathrm{q})$ & D18S64 & ?"Idd5" (1) & $\mathrm{Bcl} 2$ \\
\hline$I D D M 7$ (2q31-33) & D2S326 & ?"Idd5" (1) & Il1r/Stat1 \\
\hline IDDM8 (6q25-27) & D6S264 & None yet identified (proximal 10 or 17 ) & \\
\hline IDDM9 (3q21-q25) & D3S1303 & None yet identified (middle 6 ) & \\
\hline IDDM1O (10p11.2-q11.2) & GAD2 & None yet identified (proximal 2) & \\
\hline IDDM11 (14q24.3-q31) & D14S67 & None yet identified (middle 12) & \\
\hline IDDM12 (2q31-33) & & ?"Idd5.1" (1) & Ctla4 \\
\hline IDDM13 (2q34) & IGFBP-2,5 & ?"Idd5.2”(1) & Slc11a1 (Nramp) \\
\hline$G C K(7 \mathrm{p})$ & GCK & None yet identified (proximal 11) & \\
\hline IDDM15 (6q21) & D6S283 & ?"Idd14" (13) & D13Mit61 \\
\hline IDDM16? (1p36.1-p35) & NHE1 & ?"Idd11" (4) & Slc9a1 (Nhe1) \\
\hline
\end{tabular}

NOTE: This table was adapted from Molecular Pathology of Insulin Dependent Diabetes Mellitus. ${ }^{27}$ Idd nomenclature is placed in quotation marks because there are multiple Idd loci on mouse chromosome 1.

Abbreviations: GCK, glucokinase; HLA, human leukocyte antigen; Idd, insulin-dependent diabetes; IDDM, insulin-dependent diabetes mellitus; NOD, nonobese diabetic.

components ( $\mathrm{C} 4 \mathrm{~A}, \mathrm{C} 4 \mathrm{~B}$, factor $\mathrm{B}$, and $\mathrm{C} 2$ ), tumor necrosis factor $\alpha$ and tumor necrosis factor $\beta$, and the 21-hydroxylase genes (CYP21P and CYP21).

Polymerase chain reaction studies ${ }^{34}$ have provided researchers with a rapid means of estimating T1D susceptibility in comparison with serological techniques. Polymerase chain reaction amplification of individuals' HLA alleles in a variety of racial and ethnic groups has revealed that the presence of a specific human $\mathrm{DQ} \beta$ chain variant encoding a neutral amino acid (alanine, valine, or serine), rather than aspartic acid at position 57 (non-Asp-57), is strongly associated with T1D. In contrast, negatively charged aspartic acid at position 57 of the $\mathrm{DQ} \beta$ chain (Asp57) appears to confer resistance to T1D progression. This association is much stronger than the association between HLA-DR3 and HLA-DR4 and the presence of the disease (Tables 1 and 2). ${ }^{35-37}$

Susceptibility to T1D is mainly conferred by specific polymorphic regions within the MHC complex, such as HLA DR/DQ alleles. ${ }^{35,36}$ The genotype associated with the highest risk for T1D is the DR3/4DQ8 (DQ8 is DQA1*0301, DQB1*0302) heterozygous genotype. The HLA genotype DQB1*0602 confers dominant protection against T1D.

There is evidence that risk for islet autoimmunity increases in DR3/4-DQ8 siblings who share both HLA haplotypes with their diabetic proband sibling (63\% by age 7 and $85 \%$ by age 15) in comparison with siblings who do not share both HLA haplotypes with their diabetic proband sibling. ${ }^{38}$ These findings indicate that HLA genotyping at birth may identify individuals at high risk of developing the disease with no detectable signs of islet autoimmunity, who could then be enrolled in intervention trials aimed at preventing overt disease.

The mechanisms by which the class II genes can influence susceptibility to or protection from T1D are still the subject of discussion. Brown et al. ${ }^{39,40}$ characterized the structure of the crystallized HLA class II molecule. One hypothesis is that effective antigen binding depends on the conformation of the antigen-binding site on the DQ dimer. The 2 critical residues, DQ $\alpha$ Arg-52 and DQ $\beta$ Asp-57, are located at opposite ends of the $\alpha$-helices that form the antigen-binding site of the DQ molecule. It has been postulated that a substitution of an amino acid residue at these positions of the DQ molecule leads to conformational changes of the antigen-binding site and consequently to a modification of the affinity of the class II molecule for the diabetogenic peptide(s). ${ }^{37}$ As support for this hypothesis, it is known that Asp-57 is involved in hydrogen and salt bonding with both the peptide main chain and the DR $\alpha$ Arg-76 side chain. Theoretically, modifications in the $\mathrm{DR} \alpha \operatorname{Arg}-76$ residue would also alter the antigen-binding site. It is noteworthy that studies of the regulatory regions of the genes encoding DQ $\alpha$ and DQ $\beta$ chains have shown that the level of transcription of these genes may influence the amount of antigen binding. An increased level of production of a class II chain may increase the availability ${ }^{41}$ for dimerization. ${ }^{42}$ Studies by Demotz et $a l .{ }^{43}$ have suggested that relatively few class II 
heterodimers need to be present on the surface of an APC to efficiently crosslink the T cell receptor (TCR) and initiate a $\mathrm{T}$ cell response.

\section{ENVIRONMENTAL FACTORS INFLUENCING TYPE 1 DIABETES}

Although T1D has long been considered to be directly linked to genetic factors, researchers have been searching for environmental factors capable of triggering T1D progression. Epidemiologists have examined trends for environmental triggers through major geographical variations in T1D incidence, temporal trends in the incidence of T1D, and migration studies. ${ }^{44}$ The responsibility of environmental factors for T1D is strongly supported by statistical evidence showing that the incidence of newly diagnosed T1D subjects with high-risk HLA genotypes has decreased over the last decades, whereas newly diagnosed T1D with low-risk or even protective HLA genotypes has increased. ${ }^{45,46}$ Specific environmental factors that have been investigated include dietary compounds, including cow's milk, wheat gluten, soy products, fats, and even coffee or tea, along with vitamin deficiencies, $N$-nitroso compounds and other toxins, and viral infections. ${ }^{44}$ One specific hypothesis associates the development of T1D in Finland with seasonal changes in climate, it being more common during the cold season. ${ }^{47,48}$ Although the genetic argument has long been considered the main factor in triggering T1D, new studies are pointing to the importance of the environment.

\section{VIRAL TRIGGERS OF TYPE 1 DIABETES}

Although multiple environmental factors have been implicated as possible triggers of T1D, viral disease induction has long been argued as one of the main potential environmental triggers. Viruses in general have been receiving much attention as possible triggers in T1D because of their ability to mechanistically generate an active immune response when encountered in the host. In the case of T1D, the host environment is primed with immune cells poised to activate; all they need is an immunological stimulus. Researchers in the aforementioned seasonal pattern study on T1D induction even argue that the primary culprit responsible for triggering induction of disease during the winter season may actually be viral infections. ${ }^{47,48}$ Several viruses have been directly implicated as potential triggers of T1D, including enterovirus, adenovirus, Coxsackie B virus, cytomegalovirus, hepatitis C virus, mumps virus, rotavirus, and rubella virus. ${ }^{49-56}$ The presence of a viral infection can lead to immune cell activation through various possible mechanisms. Viruses may directly alter a host cell or tissue in such a manner that the immune system identifies it as an immunological target. Targeted host cells are lysed, releasing self peptides and fragments of the host cell into the circulation, where they may be processed and presented via APCs. ${ }^{49,54}$ Viruses can directly alter the immune system of the host by inducing polyclonal B cell activation, the release of lymphokines, the activation of immune cells, and the disruption of the strict immune balance between $\mathrm{T}$ helper 1 and $\mathrm{T}$ helper 2 type responses, thus promoting unwarranted immune activation. ${ }^{54}$ It has been hypothesized that antiviral antibodies also can lead to the formation of anti-idiotypic antibodies, which can become autoreactive if the first antibody is generated against the part of the virus that interacts with the host. ${ }^{54}$

Molecular mimicry is by far one of the most well studied processes associated with viral triggering mechanisms and T1D disease induction. Viruses produce proteins similar to those of the host. Although not all viral proteins share homology with the host, certain viral components share a distinct homology with identified $\beta$-cell antigens targeted in an autoimmune response. ${ }^{44,54}$ Upon reacting to a viral infection, the immune system may process and present a homologous viral protein in such a manner that the epitope targeted by the immune system can interact with both self and viral proteins. This process becomes especially important with respect to T1D disease induction if the homologous viral protein that is recognized and processed shares a distinct homology with $\beta$-cell-associated proteins. Unintentional activation of an immune response geared toward $\beta$-cell-associated proteins put together with epitope spreading of antigens is a volatile combination for the host.

GAD is a well-defined example of an autoantigen in T1D that shares homology with viral proteins. Researchers have demonstrated that GAD peptides share mimicry with the $\mathrm{P} 2-\mathrm{C}$ viral sequence of the Coxsackie B virus and the major outer capsid protein of rotavirus. ${ }^{55,56}$ Immunization studies of mice using homologous Coxsackie viral sequences have induced $\mathrm{T}$ cell immune responses that cross-react with GAD peptides, showing that viral homology may induce responses to self proteins. ${ }^{57}$ Furthermore, researchers have linked rotavirus infection and pancreatic islet autoimmunity in children on the HLA-DR 4 background, linking both viral induction and genetic susceptibility. ${ }^{56}$ Researching molecular 
mimicry and viral induction of T1D provides a pivotal bridge between an environmental factor and an immunological system responsible for T1D. Whether T1D is triggered environmentally, genetically, or in combination, it is still not known how exactly to prevent disease progression once it starts. Several other unknown immunological factors may play a role in triggering T1D.

\section{INNATE IMMUNE SYSTEM}

The innate immune system is the body's first line of defense against invading microbes and pathogens. Although this system does not generate long-term antigen-specific immunological memory, this system does have a high degree of immunological specificity when encountering potential pathogens. ${ }^{8}$ The innate immune system is composed of macrophages, dendritic cells, natural killer cells, neutrophils, and epithelial cells, all of which have their own unique role in the framework of an innate response. The role of the innate immune system is to survey and detect pathogens via host cell receptors that are able to recognize common structural elements expressed by pathogens. These pattern recognition receptors (PRRs), though specific, are not clonal and lack the ability for clonal expansion of cells, as seen in the adaptive immune system. ${ }^{58-60}$

Cells of the innate immune system use several types of PRRs to help initiate an immune response. Toll-like receptors (TLRs) are an evolutionarily conserved class of PRRs, which when activated cause the activation of the immune system. ${ }^{58,60,61}$ These receptors recognize specific microbial membrane components, bacterial flagellin, and DNA and RNA from bacteria and viruses. ${ }^{63}$ Upon recognition of a ligand, TLR activation brings about a cascade of proinflammatory cellular responses, including up-regulated production of cytokines, chemokines, and costimulatory molecules. ${ }^{58,62-65}$ TLRs recognize numerous self-expressed mammalian molecules in addition to the known nonself molecules. ${ }^{66}$ These self antigens are usually indicators of stress and disease or are molecules that are modified because of the disease. ${ }^{66,67}$

Once the innate immune system becomes activated, it in turn has the ability to promote activation of the adaptive immune system. ${ }^{58,62-65}$ The activation of the innate immune system is a prerequisite for the initiation of specific adaptive immune responses, such as T-helper 1 type responses. ${ }^{59,67,68}$ It has been suggested that in T1D and other autoimmune diseases, TLRs may be priming an unwarranted adaptive immune response because of autoreactive processes directed against self antigens. ${ }^{69,70}$ Innate immune cells activated against self antigens may be responsible for a break in tolerance. Once tolerance is broken, the body may promote autoreactive immune responses.

TLRs are not the only PRRs used by cells of the innate immune system. Non-TLR PRRs include Nod-like Receptors (NLRs), Triggering Receptors Expressed on Myeloid Cells (TREMs), and C-type Lectin Receptors (CLRs) have not been directly linked to autoimmunity or T1D, but represent a new class of receptors that may be responsible for triggering autoimmune responses or autoimmune initiation of the adaptive immune system. ${ }^{74-76}$ Any immunological trigger directed against self is potentially dangerous. Innate immune cells triggered via self ligand binding to TLRs or non-TLR PRRs could in turn activate $\mathrm{T}$ cells and an adaptive immune response because of the production of cytokines and other inflammatory signals. Once the balance of the immune system is flipped toward autoreactivity, negative outcomes are sure to follow.

The innate immune system has been well studied in the context of T1D development in both humans and the NOD mouse. T1D disease progression has been characterized in the 2 phase processes of asymptomatic inflammation of the islets followed by autoimmune destruction of the islets. During phase 1 , macrophages infiltrate the pancreatic islets and may be responsible for the asymptomatic inflammation that takes place there. ${ }^{8-13}$ Once activated, macrophages can secrete nitrogen and oxygen free radicals, as well as inflammatory cytokines, into their surrounding microenvironment. ${ }^{74}$ These molecules can either directly damage surrounding cells or initiate cellular damage by in turn activating other cell types to cause damage. It has even been illustrated that without the presence of macrophages in NOD mice, differentiation of $\beta$-cell-cytotoxic T cells does not take place..$^{75-77}$ Restoring macrophages in these types of depletion experiments restores the ability of $\beta$-cell-cytotoxic T cell generation, ${ }^{75-77}$ thus illustrating the importance of macrophages in T1D disease progression. The innate and adaptive immune systems communicate using an intricate system of checks and balances. Once one end of the system becomes disrupted, the whole system can falter.

\section{ADAPTIVE IMMUNE SYSTEM}

The adaptive immune system is the body's second line of defense against pathogens and disease, 
activated by the innate immune system. This system is antigen-specific, facilitating the generation of immunological memory, which serves to eliminate reoccurring pathogens more effectively upon repeat exposure to a given pathogen. This highly specific system uses receptor interaction between $\mathrm{T}$ cells and APCs to determine self from nonself. The hallmarks of an adaptive immune response are the generation of long-term immunological memory, peptide presentation in the context of MHCs, and the production of antigen-specific antibodies. ${ }^{78}$

$\mathrm{T}$ lymphocytes and their specific TCRs are a crucial part of the adaptive immune system. T lymphocytes are generated in the thymus, each having its own structurally diverse and unique antigen-recognizing receptor known as the TCR. The TCR recognizes processed antigenic peptides presented in the context of MHC via APCs. Once recognition of a peptide-bound MHC complex occurs via the TCR, a cascade of signaling events takes place, leading to either a CD4+ T cell or CD8+ T cell response, depending on which class of MHC, either MHC class I or MHC class II, was initially recognized by the TCR. Ultimately, once a TCR recognizes a processed peptide in the context of an MHC, immunological events take place that bring about either the direct targeted destruction of cells presenting the peptide or the generation of an antibody response and further $\mathrm{T}$ cell activation.

In phase 2 of T1D disease progression, both $\mathrm{T}$ and $\mathrm{B}$ lymphocytes accumulate in an islet lesion, where they can be activated against self antigens to trigger an immunological response toward the self. This autoreactive immune response then leads to the destruction of the insulin-producing $\beta$-cell within the pancreas. Both MHC class I and MHC class II restricted $\mathrm{T}$ cells are necessary for T1D disease progression in both humans and NOD mice. ${ }^{79,80}$ Antiinsulin $\mathrm{CD}+4 \mathrm{~T}$ cell populations have been reported in NOD mice. It is thought that interactions between insulin peptides and MHC molecules can cause the development of an autoimmune $\mathrm{T}$ cell repertoire. ${ }^{81}$ Although this process is not totally understood, it is necessary to determine what exact factors are causing the immune system to become unregulated in such a manner as to promote an autoimmune response.

\section{REGULATION VIA T CELLS}

Keeping the immune system tolerant is a strict balancing act: excessive regulation restricts proper immune function, whereas a lack of regulation permits overt immune function with the potential to target the self. Regulating when an immune response begins, continues, and ends is a very important part of the immune system's checks and balances. Regulatory $\mathrm{T}$ cells (T regs) and natural killer T (NKT) cells are 2 subtypes of $\mathrm{T}$ cells that are important regulators in the progression of T1D and autoimmune diseases.

$\mathrm{T}$ regs are a unique population of $\mathrm{T}$ cells that express the forkhead transcription factor forkhead box P3 (FOXP3) and are $\mathrm{CD}+4 \mathrm{CD}+25 . .^{91-93}$ $\mathrm{T}$ regs are well-known immunoregulators that can suppress proliferation of effector cells by shutting down IL-2 activation pathways. ${ }^{85} \mathrm{~T}$ regs help the immune system maintain proper $\mathrm{T}$ cell homeostasis by preventing $\mathrm{T}$ cell activation, and this in turn leads to the development of inflammatory responses. ${ }^{86,87} \mathrm{~T}$ regs work to shut off an active $\mathrm{T}$ cell response and are thought to prevent autoimmune development by regulating the expansion of $\mathrm{T}$ cell populations, $\mathrm{T}$ cell differentiation, and effector $\mathrm{T}$ cell function. ${ }^{88}$ Although individuals with T1D have numbers of $\mathrm{T}$ regs equal to those of normal healthy individuals, ${ }^{89-91} \mathrm{~T}$ regs from T1D individuals display decreased suppressive characteristics, which suggest a defect in $\mathrm{T}$ reg function in people suffering from T1D. ${ }^{89,90}$ Adoptive transfer experiments using T regs in NOD mice have effectively been demonstrated to protect against the onset and progression of T1D. ${ }^{92}$ Although current use of $\mathrm{T}$ regs in NOD mice shows promising therapeutic qualities, the potential use of T regs in humans is not sufficiently understood.

NKT cells share similar characteristics with both natural killer cells and $\mathrm{T}$ cells. These cells can cause direct cell lysis due to Fas-ligand interactions and induce cytotoxic damage of cells due to IFNg, like Natural Killer cells ${ }^{102-104}$, but they are also similar to $\mathrm{T}$ cells in that they are biased toward TCR usage and produce IL-4. ${ }^{102-104}$ When activated, NKT cells produce IL-4, which inhibits inflammatory $\mathrm{T}$ helper 1 type responses and promotes inhibitory $\mathrm{T}$ helper 2 type responses. ${ }^{96,97}$ Individuals suffering from T1D show a decreased number of NKT cells along with a decreased ability to produce and secrete IL- $-4 .{ }^{98}$ As seen with $\mathrm{T}$ regs, adoptive transfer experiments with NKT cells effectively protect against the onset and progression of T1D in NOD mice. ${ }^{99}$ Because of these 2 types of $\mathrm{T}$ cells, individuals that cannot inhibit or properly regulate $\mathrm{T}$ cell responses face increased autoimmune problems.

\section{CONCLUDING REMARKS}

T1D results from autoimmune destruction/dysfunction of insulin-secreting cells. Under physiologic 
conditions, there is balance between pathogenic $\mathrm{T}$ cells that mediate disease such as $\mathrm{T}$ cells with marked conservation of their TCRs (eg, insulin) and regulatory cells that control autoimmunity. In T1D and other autoimmune disorders, there is an altered balance between pathogenic and $\mathrm{T}$ regs.

Autoantibodies are some of the most potent risk determinants for autoimmune diseases, with relative risk exceeding 100 when all 4 autoantibodies are present in an asymptomatic child. The archetypical model for the application of autoantibodies is T1D. Seminal studies have suggested that using a combination of humoral immunological markers gives a higher predictive value for T1D progression and greater sensitivity without a significant loss of specificity. There is a growing effort as well as a large opportunity for exploring novel strategies alone or in combination with immunomodulation with the ultimate goal of finding the cure for T1D.

Emerging evidence indicates that in silico research is complementary to current experimental approaches in T1D research and has the potential not only to assist researchers in designing laboratory experimentation but also to build a framework of data collection to predict the outcome of therapeutic strategies aimed at halting the $\beta$ cell-specific autoimmune process. With support from the Juvenile Diabetes Research Foundation, the Institute for Systems Biology has generated a T1D database (T1Dbase) with numerous data sets of molecular signatures of T1D (http://t1dbase.org/cgibin/dispatcher.cgi/welcome/display). Molecular signatures have revealed remarkable differentiation of organ-specific complications as reflected in the work of the Kretzler laboratory on transcription factor binding site patterns in nephropathy associated with T2DM versus nephropathy due to lupus erythematosus, glomerulonephritis, or other causes. ${ }^{100,101}$ Similar studies on T1D-associated neuropathy, are being completed by our group at the National Center for Integrative Biomedical Informatics (https://portal.ncibi.org/portal). Mathematical modeling of the imbalance of T cell subsets in T1D, in work led by Patrick Nelson, is expected to inform our future work.

\section{ACKNOWLEDGMENT}

This work was supported by the National Institutes of Health (grants RO1 DK53456, DK56200, and NIDDK PA-04-081 to M.P.) and by the University of Michigan Center for Computational Medicine and Biology Pilot Research Program. The authors gratefully thank the Brehm Coalition for its support. Any research involving human subjects was conducted in accordance with the guidelines of the Declaration of Helsinki and was approved by the institutional review board; all subjects provided informed consent.

\section{DISCLOSURES}

Potential conflict of interest: Nothing to report.

\section{REFERENCES}

1. Janeway CA, Travis P, Walport M, Shlomchik M. Immunobiology. 6th ed. New York, NY: Garland Science; 2007.

2. Bardsley JK, Want LL. Overview of diabetes. Crit Care Nurse Q 2004; 27: 106-112.

3. Pietropaolo M, Barinas-Mitchell E, Kuller LH. Perspectives in diabetes heterogeneity of diabetes mellitus. Unraveling a dispute: is systemic inflammation related to islet autoimmunity? Diabetes 2007; 56: 1189-1197.

4. Delovitch TL, Singh B. The nonobese diabetic mouse as a model of autoimmune diabetes: immune dysregulation gets the NOD. Immunity 1997; 7: 727-738.

5. Katz JD, Benoist C, Mathis D. T helper cell subsets in insulin-dependent diabetes. Science 1995; 268: $1185-1188$.

6. Rabinovitch A, Suarez-Pinzon WL, Sorensen O. Interleukin 12 mRNA expression in islets correlates with beta-cell destruction in NOD mice. J Autoimmun 1996; 9: 645-651.

7. Von Herrath MG, Oldstone MB. Interferon-gamma is essential for destruction of beta-cells and development of insulin-dependent diabetes mellitus. J Exp Med 1997; 185: 531-539.

8. Wong FS, Janeway CA. The role of CD4 and CD8 $\mathrm{T}$ cells in type 1 diabetes in the NOD mouse. Res Immunol 1997; 148: 327-332.

9. Yoon JW, Jun HS, Santamaria P. Cellular and molecular mechanisms for the initiation and progression of beta-cell destruction resulting from the collaboration between macrophages and $\mathrm{T}$ cells. Autoimmunity 1998; 127: 109-112.

10. Lee KU, Kim MK, Amano K, et al. Preferential infiltration of macrophages during early stages of insulitis in diabetes-prone BB rats. Diabetes 1989; 37: 1053-1058.

11. Voorbij HA, Jeucken PH, Kabel PJ, et al. Dendritic cells and scavenger macrophages in pancreatic islets of pre-diabetic BB rats. Diabetes 1989; 38: 1623-1629.

12. Jansen A, Homo-Delarche F, Hooijkaas H, et al. Immunohistochemical characterization of monocytemacrophage and dendritic cells in the initiation of insulitis and beta cell destruction in NOD mice. Diabetes 1994; 43: 667-675.

13. Lee KU, Amano K, Yoon JW. Evidence for initial involvement of macrophages in development of insulitis in NOD mice. Diabetes 1988; 37: 989-991. 
14. Kawasaki E, Gill RG, Eisenbarth GS. Type 1 Diabetes Mellitus. Austin, TX: Landes Bioscience; 1999.

15. Yoon JW, Jun HS. Cellular and molecular pathogenic mechanisms of insulin-dependent diabetes mellitus. Ann N Y Acad Sci 2001; 928: 200-211.

16. Pearl-Yafe M, Kaminitz A, Yolcu ES, et al. Pancreatic islets under attack: cellular and molecular effectors. Curr Pharm Des 2007; 13: 749-760.

17. Estella E, McKenzie MD, Catterall, et al. Granzyme Bmediated death of pancreatic beta-cells requires the proapoptotic BH-3only molecule bid. Diabetes 2006; 55: 2212-2219.

18. Kawasaki E, Abiru N, Eguchi K. Prevention of type 1 diabetes: from the view point of beta cell damage. Diabetes Res Clin Pract 2004; 55(suppl 1): S27-S32.

19. Ichinose K, Kawasaki E, Eguchi K. Recent advancement of understanding pathogenesis of type 1 diabetes and potential relevance to diabetic nephropathy. Am J Nephrol 2007; 27: 554-564.

20. Atkinson MA, Eisenbarth GS. Type I diabetes: new perspectives on disease pathogenesis and treatment. Lancet 2001; 358: 221-229.

21. Finegood DT, Scaglia L, Bonner-Weir S. Dynamics of $\beta$-cell mass in the growing rat pancreas. Estimation with a simple mathematical model. Diabetes 1995; 44: 249-256.

22. Nakayama M, Abiru N, Moriyama H, et al. Prime role for an insulin epitope in the development of type 1 diabetes in NOD mice. Nature 2005; 435: 220-223.

23. Hutton JC, Wenzlau JM, Juhl K, et al. The cation efflux transporter ZnT8 (Slc30A8) is a major autoantigen in human type 1 diabetes. PNAS 2007; 104: $17040-17045$.

24. Herrath MV, Sanda S, Herold K. Type 1 diabetes as a relapsing-remitting disease? Nat Rev Immunol 2007; 7: 988-994.

25. Pietropaolo M, Yu S, Libman IM, et al. Cytoplasmic islet cell antibodies remain valuable in defining the risk of progression to type 1 diabetes in subjects with other autoantibodies. Pediatr Diabetes 2005; 6: 184-192.

26. Nepom, GT. Class II antigens and disease susceptibility. Annu Rev Med 1995; 46: 17-25.

27. Serreze DV, Leiter EH. Molecular pathology of insulin dependent diabetes mellitutus. Current Directions in Autoimmunity. 2001; 4: 31-67.

28. Redondo MJ, Fain PR, Krischer P, et al. Expression of beta-cell autoimmunity does not differ between potential dizygotic twins of siblings of patients with type 1 diabetes. J Autoimmun 2004; 23: 275-279.

29. Thomson G. HLA DR antigens and susceptibility to insulin-dependent diabetes mellitus. Am J Hum Genet 1984; 36: 1309-1317.

30. Todd JA, Walker NM, Cooper JD, et al. Robust associations of four new chromosome regions from genome-wide analyses of type 1 diabetes. Nat Genet 2007; 39: 857-864.

31. Powis SH, Mockridge I, Kelly A, et al. Polymorphism in a second $\mathrm{ABC}$ transporter gene located within the class II region of the human major histocompatibility complex. Proc Natl Acad Sci U S A 1992; 89: 1463-1467.

32. Colonna M, Bresnahan M, Bahram S, et al. Alleleic variants of the human putative peptide transporter involved in antigen processing. Proc Natl Acad Sci U S A 1992; 89: 3932-3936.
33. Germain RN. MHC-dependent antigen processing and peptide presentation: providing ligands for $\mathrm{T}$ lymphocyte activation. Cell 1994; 76: 287-299.

34. Rudert WA, Trucco M. Rapid detection of sequence variation using polymers of specific oligonucleotides. Nucleic Acid Res 1992; 5: 1146.

35. Todd JA, Bell JI, McDevitt HO. HLA-DQ $\beta$ gene contributes to susceptibility and resistance to insulindependent diabetes mellitus. Nature 1987; 329: 599-604.

36. Morel PA, Dorman JS, Todd JA, et al. Aspartic acid at position 57 of the HLA-DQ beta chain protects against type I diabetes: a family study. Proc Natl Acad Sci U S A 1988; 85: 8111-8115.

37. Trucco M. To be or not to be ASP 57, that is the question. Diabetes Care 1992; 15: 705-715.

38. Aly TA, Ide A, Jahromi MM, et al. Extreme genetic risks for type 1A diabetes. Proc Natl Acad Sci US A 2006; 103: 14074-14079.

39. Brown JH, Jardetzky T, Saper MA, et al. A hypothetical model of the foreign antigen binding site of class II histocompatibility molecules. Nature 1988; 332: $845-850$.

40. Brown JH, Jardetzky TS, Gorga JC, et al. Threedimensional structure of the human class II histocompatibility antigen HLA-DR1. Nature 1993; 364: 33-39.

41. Jardetzky TS, Brown JH, Gorga JC, et al. Three-dimensional structure of a human class II histocompatibility molecule complexed with superantigen. Nature 1994; 368: 711-718.

42. Turco E, Manfras BJ, Ge L, et al. The x boxes from promoters of HLA class II B genes at different loci do not compete for nuclear protein-specific binding. Immunogenetics 1990; 32: 117-128.

43. Demotz S, Grey HM, Sette A. The minimal number of class II MHC-antigen complexes needed for T cell activation. Science 1990; 249: 1028-1030.

44. Akerblom HK, Knip M. Putative environmental factors in type 1 diabetes. Diabetes Metab Rev 1998; 14: $31-67$.

45. Herman R, Knip M, Veijola R, et al. The FINDIANE Study Group: temporal changes in the frequencies of HLA genotypes in patients with type 1 diabetes: indication of an increased environmental pressure? Diabetologia 2003; 46: 420-425.

46. Gillespie KM, Bain SC, Barnett AH, et al. The rising incidence of childhood type 1 diabetes and reduced contribution of high-risk HLA haplotypes. Lancet 2004; 364: 1645-1647.

47. Kimpimaki T, Kupila A, Hamalaninen AM, et al. The first signs of B-cell autoimmunity appear in infancy in genetically susceptible children from the general population: the Finnish Type 1 Diabetes Prediction and Prevention Study. J Clin Endocrinol Metab 2001; 86: $4782-4788$.

48. Laron Z. Lessons from recent epidemiological studies in type 1 childhood diabetes. I Pediatr Endocrinol Metab 1999; 12(suppl 3): 733-736.

49. Yoon JW. Role of viruses in the pathogenesis of IDDM. Ann Med 1991; 23: 437-445.

50. Varela-Calvino R, Peakman M. Enteroviruses and type 1 diabetes. Diabetes Metab Res Rev 2003; 19: 431-441.

51. Green J, Casabonne D, Newton R. Coxsackie B virus serology and type I diabetes mellitus: a systemic 
review of published case-control studies. Diabet Med 2004; 21: 507-514.

52. Barbu AR, Akusjarvi G, Welsh N. Adenoviral-mediated transduction of human pancreatic islets: importance of adenoviral genome for cell viability and association with a deficient antiviral response. Endocrinology 2005; 146: 2406-2414.

53. Chen LK, Chou YC, Tsai ST, et al. Hepatitis C virus infection-related type 1 diabetes mellitus. Diabet Med 2005; 22: 340-343.

54. Jun HS, Yoon JW. A new look at viruses in type 1 diabetes. Diabetes Metab Res Rev 2002; 19: 8-31.

55. Honeyman MC, Coulson BS, Stone NL, et al. Association between rotavirus infection and pancreatic islet autoimmunity in children at risk of developing type 1 diabetes. Diabetes 2000; 49: 1319-1324.

56. Atkinson, MA, Bowman MA, Campbell L, et al. Cellular immunity to a determinant common to glutamic decarboxylase and Coxsackie virus in insulin-dependent diabetes. J Clin Invest 1994; 94: 2125-2129.

57. Titan J, Lehmann PV, Kaufman DL. T cell crossreactivity between Coxsackie virus and glutamate decarboxylase is associated with a murine diabetes susceptibility allele. J Exp Med 1994; 180: 1979-1984.

58. Takeda K, Kaisho T, Akira S. Toll-like receptors. Annu Rev Immunol 2003; 21: 335-376.

59. Dabbagh K, Lewis DB. Toll-like receptors and Thelper-1/T-helper-2 responses. Curr Opin Infect Dis 2003; 16: 199 .

60. Pasare C, Medzhitov R. Toll-like receptors and acquired immunity. Semin Immunol 2004; 16: 23-26.

61. Akira S, Uematsu S, Takeuchi O. Pathogen recognition and innate immunity. Cell 2006; 124: 783-801.

62. Godfrey DI, Hammond KJ, Poulton LD, et al. NKT cells: facts, functions and fallacies. Immunol Today 2000; 21: 573-583.

63. Medzhitov R. Toll-like receptors and innate immunity. Nat Rev Immunol 2001; 1: 135-145.

64. Akira S, Takeda K. Toll-like receptor signaling. Nat Rev Immunol 2004; 4: 499-511.

65. Kawai T, Akira S. TLR signaling. Nature 2006; 13: $816-825$.

66. Johnson GB, Brunn GJ, Platt JL. Activation of mammalian Toll-like receptors by endogenous agonists. Crit Rev Immunol 2003; 23: 15.

67. Termeer C, Benedix F, Sleeman, J, et al. Oligosaccharides of hyaluronan activate dendritic cells via toll-like receptor 4. J Exp Med 2002; 195: 99.

68. Buttari B, Profumo E, Mattei V, et al. Oxidized beta2glycoprotein I induces human dendritic cell maturation and promotes a $\mathrm{T}$ helper type 1 response. Blood 2005; 106: 3880.

69. McSorley SJ, Ehst BD, Yu Y, Gewirtz AT. Bacterial flagellin is an effective adjuvant for CD4+ T cells in vivo. J Immunol 2002; 169: 3914-3919.

70. Martin DA, Elkon KB. Autoantibodies make a U-turn: the toll hypothesis for autoantibody specificity. $J$ Exp Med 2005; 202: 1465-1469.

71. Fritz JH, Le Bourhis L Sellge G, et al. Nod-like proteins in immunity, inflammation and disease. Nat Immunol 2006; 12: 1250-1257.
72. Klesney-Tait J, Turnbull IR, Colonna M. The TREM receptor family and signal integration. Nat Immunol 2006; 12: 1266-1273.

73. Robinson MJ, Sancho D, Slack EC, et al. Myeloid Ctype lectins in innate immunity. Nat Immunol 2006; 12: $1258-1265$.

74. Beyan H, Buckley LR, Yousaf N, et al. A role for innate immunity in type 1 diabetes? Diabetes Metab Res Rev 2003; 19: 89-100.

75. Jun HS, Yoon CS, Zbytnuik L, et al. The role of macrophages in T-cell mediated autoimmune diabetes in nonobese diabetic mice. J Exp Med 1999; 189: 347-358.

76. Oschilewski U, Kiesel U, Kolb H. Administration of silica prevents diabetes in BB rats. Diabetes 1985; 34 : 197-199.

77. Lee KU, Pak CY, Amano K, Yoon JW. Prevention of lymphocytic thyroditis and insulitis in diabetes prone $\mathrm{BB}$ rats by the depletion of macrophages. Diabetologia 1988; 31: 400-402.

78. Medzhitov R, Janeway CA Jr. Innate immunity: the virtues of a nonclonal system of recognition. Cell 1997; 91: 295-298.

79. Bottazzo GF, Dean BM, McNally JM, et al. In situ characterization of autoimmune phenomena and expression of HLA molecules in the pancreas in diabetic insulitis. New Engl J Med 1985; 313: 353-360.

80. Conrad B, Weidman E, Trucco G, et al. Evidence for superantigen involvement in insulin-dependent diabetes mellitus etiology. Nature 1994; 371: 351-355.

81. Levisetti MG, Suri A, Petzold SJ, Unanue ER. The insulin-specific $\mathrm{T}$ cells of nonobese diabetic mice recognize a weak MHC-binding segment in more than one form. J Immunol 2007; 178: 6051-6057.

82. Khatrri R, Cox T, Yasayko SA, Ramsdell F. An essential role for scurfin in $\mathrm{CD}+4 \mathrm{CD}+25$ T-regulatory cells. Nat Immunol 2003; 4: 337-342.

83. Fontenot JD, Gavin MA, Rudensky AY. FoxP3 programs the development and function of $\mathrm{CD}+4$ CD+25 regulatory T-cells. Nat Immunol 2003; 4: 330-336.

84. Hori S, Nomura T, Sakaguchi S. Control of regulatory $\mathrm{T}$ cell development by the transcription factor Foxp3. Science 2004; 299: 1057-1061.

85. Randolph DA, Fathman CG. CD $4 \mathrm{CD}+25$ regulatory T cells and their therapeutic potential. Annu Rev Med 2006; 57: 381-402.

86. St. Clair EW, Turka LA, Saxon A, et al. New reagents on the horizon for immune tolerance. Annu Rev Med 2007; 58: 329-346.

87. Bluestone JA, Tang Q. How do CD4+CD25+ regulatory $\mathrm{T}$ cells control autoimmunity? Curr Opin Immunol 2005; 17: 638-642.

88. Tang Q, Bluestone JA. Regulatory T-cell physiology and application to treat autoimmunity. Immunol Rev 2006; 212: 217-237.

89. Brusko TM, Wasserfall CH, Clare-Salzler MJ, et al. Functional defects and the influence of age on the frequency of $\mathrm{CD}+4 \mathrm{CD}+25 \mathrm{~T}$-cells in type 1 diabetes. Diabetes 2005; 54: 1407-1414.

90. Lindley S, Dayan CM, Bishop A, et al. Defective suppressor function in $\mathrm{CD}+4 \mathrm{CD}+25 \mathrm{t}$ cells from patients with type 1 diabetes. Diabetes 2005; 54: 92-99. 
91. Putnam AL, Vendrame F, Dotta F, Gottlieb PA. CD+4 $\mathrm{CD}+25$ high regulatory $\mathrm{T}$ cells in human autoimmune diabetes. J Autoimmun 2005; 24: 55-62.

92. Mason D, Powrie F. Control of immune pathology by regulatory T cells. Curr Opin Immunol 1998; 10: 649-655.

93. Bendelac A. Mouse NK+1 T cells. Curr Opin Immunol 1995; 7: 367

94. Bendelac A, Rivera MN, Park SH, Roark JH. Mouse CD1-specific NK1 T cells-development, specificity, and function. Ann Rev Immunol 1997; 15: 535-562.

95. Macdonald HR. NK1.1+ T cell receptor $-\alpha \beta+$ cell-new clues to their origin, specificity, and function. $J \operatorname{Exp}$ Med 1995; 182: 633-638.

96. Burdin N, Brossay L, Kronenberg M. Immunization with $\alpha$-galactosylceramyde polarizes CD1-reactive NK T-cells toward Th2 cytokine synthesis. Eur J Immunol 1999; 29: 2014-2025.

97. Singh N, Hong S, Scherer DC, et al. Cutting edge: activation of NK T-cells by CD1d and $\alpha$ galactosylceramyde directs conventional $\mathrm{T}$ cells to the acquisition of a Th2 phenotype. J Immunol 1999; 163: $237-2377$.

98. Wilson SB, Kent SC, Patton KT, et al. Extreme Th1 bias of invariant $\mathrm{V} \alpha 24 \mathrm{~J} \alpha \mathrm{Q}$ T cells in type 1 diabetes. Nature 1998; 391: 177-181.

99. Hammond KJL, Poulton LD, Palimsano LJ, et al. $\alpha \beta$-T cell receptor (TCR) + CD-4 CD-8 (NKT) thymocytes prevent insulin-dependent diabetes mellitus in nonobese diabetic $(\mathrm{NOD} / \mathrm{Lt})$ mice by the influence of interleukin-4 (IL-4) and/or IL-10. J Exp Med 1998; 187: 1047-1056.

100. Smink LJ, Helton EM, Healy BC, et al. T1DBase, a community web-based resource for type 1 diabetes research. Nucleic Acids Res 2005; 1(33): D544-D549.

101. Cohen CD, Klingenhoff A, Boucherot A, et al. Comparative promoter analysis allows de novo identification of specialized cell junction-associated proteins. PNAS 2006; 103: 5682-5687.

102. Anderson MS, Bluestone JA. The NOD mouse: a model of immune dysregulation. Annu Rev Immunol 2005; 23: 447-485. 